\title{
Effect of fresh fruit consumption on lung function and wheeze in children
}

\author{
Derek G Cook, Iain M Carey, Peter H Whincup, Olia Papacosta, Susanna Chirico, \\ K Richard Bruckdorfer, Mary Walker
}

\begin{abstract}
Background - Fresh fruit consumption and vitamin $C$ intake have been associated with improved lung function in adults. Whether this is due to enhancement of lung growth, to a reduction in lung function decline, or to protection against bronchospasm is unclear.

Methods - In a cross-sectional school based survey of 2650 children aged 8-11 from 10 towns in England and Wales the main outcome measure was forced expiratory volume in one second $\left(\mathrm{FEV}_{1}\right)$ standardised for body size and sex. Exposure was assessed by a food frequency questionnaire to parents and by measurement of plasma levels of vitamin $C$ in a subsample of 278 children.

Results - $\mathrm{FEV}_{1}$ was positively associated with frequency of fresh fruit consumption. After adjustment for possible confounding variables including social class and passive smoking, those who never ate any fresh fruit had an estimated $F E V_{1}$ some $79 \mathrm{ml}$ $(4.3 \%)$ lower than those who ate these items more than once a day (95\% CI 22 to $136 \mathrm{ml})$. The association between $\mathrm{FEV}_{1}$ and fruit consumption was stronger in subjects with wheeze than in non-wheezers ( $p=$ 0.020 for difference in trend), though wheeze itself was not related to fresh fruit consumption. Frequency of consumption of salads and of green vegetables were both associated with $\mathrm{FEV}_{1}$ but the relationships were weaker than for fresh fruit. Plasma vitamin $C$ levels were unrelated to $F_{1}$ $(r=-0.01, p=0.92)$ or to wheeze and were only weakly related to fresh fruit consumption $(r=0.13, p=0.055)$.

Conclusions - Fresh fruit consumption appears to have a beneficial effect on lung function in children. Further work is needed to confirm whether the effect is restricted to subjects who wheeze and to identify the specific nutrient involved.

(Thorax 1997;52:628-633)
\end{abstract}

Keywords: lung function, children, fresh fruit, vitamin C, wheeze.

Recent studies have reported infrequent fresh fruit consumption or low vitamin $\mathrm{C}$ intake to be associated with reduced lung function in adults. ${ }^{1-3}$ Interest in vitamin $\mathrm{C}$ arose out of a belief that accelerated decline in pulmonary function in smokers might be due to deficiencies of proteolytic enzymes. ${ }^{4}$ This raised the possibility that antioxidants such as as- corbate might protect against the lung damage caused by cigarette smoking. ${ }^{5}$ However, the effects are not confined to smokers ${ }^{13}$ and in one study appeared to be stronger in subjects who had never smoked and to be present in young adults, suggesting that other biological mechanisms may be required to explain reduced ventilatory function in subjects with a low fruit intake. ${ }^{2}$ Strachan suggested that the relationship in adults might be an indirect reflection of an influence of diet on lung growth in childhood. In adults it has also been suggested that any effect may be much greater amongst asthmatic subjects. ${ }^{1}$

We have examined the cross-sectional relationship between reported frequency of fresh fruit, salad, and green vegetable consumption and lung function in 9-11 year old children from 10 British towns. In addition we have examined the interactions with wheeze, and the relationship between plasma vitamin C levels and lung function in a subsample. We have focused on fresh fruit because it is both an important source of vitamin $\mathrm{C}$ and may be more important in accounting for individual differences in intake, and because of the evidence linking infrequent fresh fruit consumption to reduced lung function in adults. ${ }^{2}$

\section{Methods}

SAMPLE SELECTION

The study was carried out in 10 towns in England and Wales, five with exceptionally high adult cardiovascular mortality rates and five with exceptionally low rates. Full details are published elsewhere. ${ }^{6}$ Because of the strong geographical association between mortality from cardiovascular and respiratory disease, this resulted in there being five towns with a high mortality from respiratory diseases and five with a low mortality. ${ }^{7}$ Within each town a sample of 10 primary schools corresponding to infant schools included in an earlier study were selected. Within each school 50 children aged 9-11 were invited to participate.

\section{SURVEY PROCEDURES}

Ethical approval was obtained from all relevant local research ethics committees. Between April and November 1994 a team of four trained nurses, working in pairs, visited each town. Towns in high and low mortality areas were examined alternately. The 10 schools in each town were visited during a five-day period, each pair of nurses visiting one school for a whole day. Each nurse made approximately one quarter of all measurements in each town. 
Standing height was measured to the last complete millimetre with shoes removed, weight was measured to the last complete $0.1 \mathrm{~kg}$, and ethnic group was assessed on the basis of the child's appearance. Room temperature was measured to the nearest $0.1^{\circ} \mathrm{C}$ with an RS digital thermometer and thermocouple. Passive smoke exposure was measured from salivary cotinine levels. Subjects were asked to collect saliva in the mouth and to spit into a plastic container. Samples were frozen within eight hours of collection for later assay by gas-liquid chromatography which can detect cotinine concentrations as low as $0.1 \mathrm{ng} / \mathrm{ml}^{8}$

\section{SPIROMETRY}

Each team used one "Compact" pneumotachograph (Vitalograph Ltd, Buckingham, UK) with a paediatric mouthpiece adapter. These measure air flow through a resistive mesh, on the Fleisch principle, and determine volumes by flow integration. The pneumotachographs were calibrated twice daily by pumping five litres through the instrument using a one litre precision syringe. There was no systematic calibration drift, but machine failure during the study led to replacement of one instrument in the fourth town. After a period of instruction and two practice attempts, each child performed three forced expiratory manoeuvres according to the methods recommended by the American Thoracic Society. ${ }^{9}$ A fourth manoeuvre was performed if the best test variation was greater than $10 \%$ after three blows. Tests were performed in the standing position; nose-clips were not used. All spirometric indices were corrected automatically to BTPS. Forced expiratory volume in one second $\left(\mathrm{FEV}_{1}\right)$ and other indices were automatically recorded for the "best" test as defined by the American Thoracic Society ${ }^{9}$ that is, the spirogram with the greatest sum of $\mathrm{FEV}_{1}$ and FVC. In addition, a measure of reproducibility, the best test variation, was recorded - that is, the difference between $\mathrm{FEV}_{1}$ + FVC for the "best" test and "second best" test as a percentage of that for the "best" test.

\section{PARENTAL QUESTIONNAIRE}

A self-completion questionnaire was sent to the parents of all participants on the day of the examination and included a food frequency questionnaire, a respiratory questionnaire, and information on the child's birth weight and parental occupation. Information on birth weight was supplemented from birth record data in a small number of cases where the mother could not recall the birth weight of the child. For 10 food items parents were asked: "How often does this child eat the following foods? More than once a day; once a day; most days; one or two days a week; less than once a week; never". These categories were assigned a score from 5 (more than once a day) to 0 (never). We were specifically interested in five items: fresh fruit in summer, fresh fruit in winter, green salad in summer, green salad in winter, and green vegetables. For both fresh fruit and salads we created a score by averaging the summer and winter scores. Tests for trend were based on including this score as a continuous variable in regression models. However, because equal intervals of the score are unlikely to correspond to equal differences in nutrient intake, and because the functional form of any relationship between nutrient intake and lung function is unknown, we present standardised lung functions for subjects categorised into five groups based on the score: $0-0.5$ (never), 1-1.5, 2-3, 3.5-4, 4.5-5 (> daily). To further examine the specificity of any relationships found with items of interest we also looked at relationships of $\mathrm{FEV}_{1}$ to five other food items: fish, cheese, poultry, red meat, and processed meat.

Social class was determined for both parents on the basis of present or most recent occupation as defined by the Office of Population Censuses and Surveys 1980. Analyses in this paper refer to the head of the household. Those few households to whom a social class could not be assigned were treated as a separate group; they were mostly single parent households in which the mother had never worked regularly.

A detailed respiratory symptom questionnaire included the question: "Has this child had wheezing or whistling in the chest in the past 12 months?"

BLOOD SAMPLING AND VITAMIN C ASSAY

Blood samples were taken from the older children throughout the study. ${ }^{6}$ In the last two towns (Tunbridge Wells and Rhondda) samples of blood were anticoagulated in acid-citratedextrose. After centrifugation a $0.5 \mathrm{ml}$ sample of plasma was mixed with an equal volume of metaphosphoric acid $(10 \% \mathrm{v} / \mathrm{v})$ and snap frozen on dry ice within three hours of venepuncture. The samples were stored for a maximum of two months at $-20^{\circ} \mathrm{C}$ before analysis with high pressure liquid chromatography. ${ }^{10}$ The stability of a small number of samples was checked over a period of two months and was found not to decrease by more than $6.2 \%$ compared with fresh plasma as found in other studies. ${ }^{11}$

\section{STATISTICAL METHODS}

All analyses were carried out using the SAS statistical package (SAS Institute Inc, North Carolina, USA). Multiple regressions were performed using the GLM procedure. In model 1 $\mathrm{FEV}_{1}$ was regressed on age, sex, height, town (10 levels), instrument (three levels), observer (four levels), and room temperature as well as fresh fruit consumption to produce adjusted estimates of $\mathrm{FEV}_{1}$ by fresh fruit consumption categories. Tests for trend were obtained by including fresh fruit consumption as a continuous variable. Model 2 included two additional covariates: an obesity index ((weight 9)/height $\left.{ }^{3.7}\right)^{12}$ and its square because of evidence of non-linearity and social class (seven levels). Model 3 further adjusted for salivary concentrations of cotinine and birth weight 
Table 1 Fresh fruit consumption in summer and winter in 2650 subjects

\begin{tabular}{|c|c|c|c|c|c|c|}
\hline & \multicolumn{6}{|l|}{ Winter } \\
\hline & $\begin{array}{l}\text { More than } \\
\text { once per } \\
\text { day }\end{array}$ & $\begin{array}{l}\text { Once } \\
\text { per } \\
\text { day }\end{array}$ & $\begin{array}{l}\text { Most } \\
\text { days }\end{array}$ & $\begin{array}{l}\text { Once/twice } \\
\text { per } \\
\text { week }\end{array}$ & $\begin{array}{l}\text { Less than } \\
\text { once per } \\
\text { week }\end{array}$ & Never \\
\hline \multicolumn{7}{|l|}{ Summer } \\
\hline More than once per day & 426 & 238 & 75 & 15 & 2 & 2 \\
\hline Once per day & 3 & 400 & 106 & 41 & 4 & 1 \\
\hline Most days & 3 & 12 & 440 & 182 & 28 & 0 \\
\hline Once/twice a week & 0 & 0 & 3 & 350 & 75 & 2 \\
\hline Less than once per week & 0 & 0 & 1 & 2 & 152 & 15 \\
\hline Never & 0 & 0 & 1 & 0 & 2 & 69 \\
\hline
\end{tabular}

based on slightly fewer subjects. Birth weight was included because of evidence that respiratory function is related to intrauterine growth. ${ }^{13}$ Least squares estimates by fresh fruit consumption category were produced using the LSMEANS option.

\section{Results}

RESPONSE RATES AND MISSING DATA

Of 4711 children invited, 3728 (79\%) were screened. All analyses in this paper are restricted to white children aged 8-11 of whom 93\% (3160/3407) had a satisfactory $\mathrm{FEV}_{1}$ (including best test variation below 10\%). Questionnaire data on fresh fruit consumption were available on 2650 children with satisfactory $\mathrm{FEV}_{1}$. Both cotinine levels and birth weight were available on 2475 of these.

\section{FRESH FRUIT IN WINTER AND SUMMER}

There is a strong relationship between reported fresh fruit consumption in summer and winter, but with lower consumption in the winter (table 1). Similar results hold for salads. Our combined fruit score was correlated with both the salad score (Spearman correlation $=0.38, p$ $<0.001)$ and with green vegetable consumption (Spearman correlation $=0.27, \mathrm{p}<0.001)$.

FRESH FRUIT, SALAD AND GREEN VEGETABLE CONSUMPTION BY AGE, SEX, SOCIAL CLASS AND TOWN

Daily fresh fruit consumption is more common in girls, exhibits the expected social class gra-

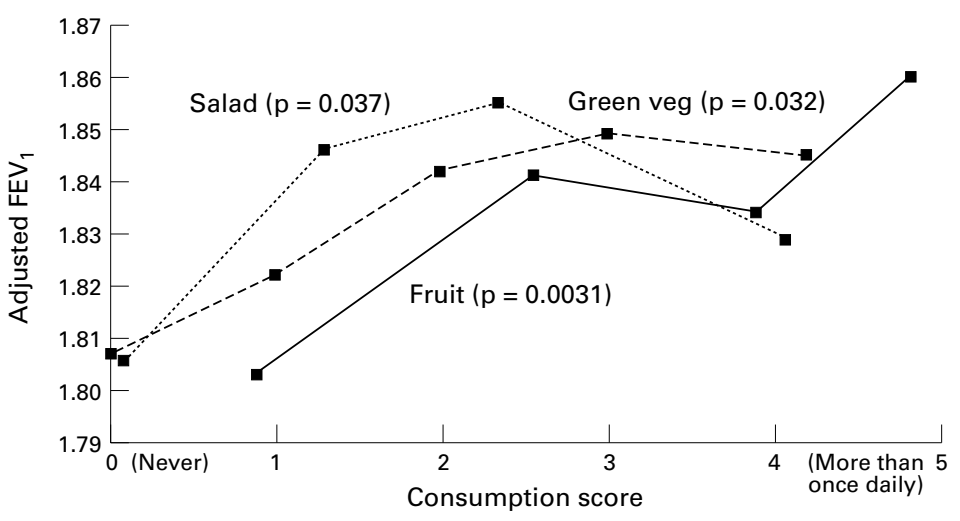

Figure 1 Relationship between frequency of consumption of fresh fruit, salad, and green vegetables and $F E V_{1}$ adjusted for age, height, sex, town, observer and room temperature (model 1). $p$ values for trend based on 2553 subjects with data on all variables.
Table 2 Fresh fruit consumption by age, sex, social class, and town

\begin{tabular}{lrll}
\hline Category & $\begin{array}{l}\text { No of } \\
\text { subjects }\end{array}$ & $\begin{array}{l}\text { \% More } \\
\text { than daily } \\
\text { (score 4.5-5) }\end{array}$ & $\begin{array}{l}\text { \% Never } \\
\text { (score 0-0.5) }\end{array}$ \\
\hline Sex & & & \\
$\quad$ Girls & 1267 & 26.8 & 2.0 \\
$\quad$ Boys & 1383 & 23.6 & 4.4 \\
Age (years) & 580 & 26.4 & 3.3 \\
<10 & 1406 & 25.2 & 3.1 \\
10 & 664 & 24.1 & 3.5 \\
11 & & & \\
Social class & 903 & 32.1 & 3.4 \\
I+ II & 315 & 21.3 & 3.5 \\
III (non-manual) & 839 & 24.7 & 3.5 \\
III (manual) & 404 & 20.0 & 2.2 \\
IV+V & 189 & 11.6 & 3.2 \\
Missing & & & \\
Town & 229 & 26.6 & 1.7 \\
Low mortality: & 291 & 22.3 & 3.4 \\
$\quad$ Esher & 243 & 32.9 & 1.2 \\
$\quad$ Chelmsford & 268 & 38.4 & 2.2 \\
$\quad$ Leatherhead & 340 & 32.4 & 1.8 \\
$\quad$ Bath & & & \\
$\quad$ Tunbridge Wells & 301 & 14.6 & 6.3 \\
High mortality: & 21.9 & 3.8 \\
$\quad$ Wigan & Port Talbot & 265 & 21.9 \\
$\quad$ Burnley & 251 & 17.1 & 4.7 \\
$\quad$ Rochdale & 171 & 24.6 & 2.9 \\
$\quad$ Rhondda & 291 & 21.0 & 3.8 \\
\hline$\quad$ & & & \\
\hline
\end{tabular}

dient, and is markedly less common in northern and Welsh towns than in our southern towns (table 2). Similar patterns exist for both salad consumption and green vegetables, but the percentages of children consuming salads and green vegetables on a more than daily basis were much lower at $1.4 \%$ and $3.1 \%$, respectively. Town and social class are thus potentially important confounding variables to allow for when looking at lung function and wheeze.

FOOD FREQUENCY QUESTIONNAIRE AND FEV $\mathrm{FEV}_{1}$ adjusted for height, age, sex, and town, as well as for observer, instrument, and room temperature (model 1) shows a positive relationship with frequency of consumption of each of fresh fruit, salad and green vegetables (fig 1). Extreme groups with few subjects were combined with their neighbours so that all points are based on more than 100 subjects. Overall, the trend is strongest for fresh fruit, and in a regression model including all three measures the fresh fruit score remained statistically significant $(p=0.029)$. A score based on all items (defined as the sum of the individual scores) was somewhat more strongly related to $\mathrm{FEV}_{1}$ than was the fresh fruit score alone (test for trend, $p=0.001$ based on model 1 ).

The frequency of consumption of four other dietary items exhibited no significant trends with $\mathrm{FEV}_{1}$ (adjusting for model 1 confounders): fish $(\mathrm{p}=0.47)$, cheese $(\mathrm{p}=0.53)$, poultry $(\mathrm{p}=$ $0.21)$, and red meat $(p=0.13)$. More frequent consumption of processed meat was weakly associated with reduced $\mathrm{FEV}_{1}(\mathrm{p}=0.051)$, but adjustment for fresh fruit weakened the strength of the association $(\mathrm{p}=0.11)$, while the coefficient for fresh fruit remained statistically significant $(\mathrm{p}=0.031)$.

The results for fresh fruit are presented in more detail in table 3 . In our basic model 1 those who never ate fresh fruit (score $=0-0.5)$ had an estimated $\mathrm{FEV}_{1}$ some $88 \mathrm{ml}$ lower than 
Table 3 Relationship between mean (SE) $F E V_{1}(l)$ and frequency of fruit consumption analysed by three models

\begin{tabular}{lrlll}
\hline Fruit score & No. & $\begin{array}{l}\text { Model 1 } \\
(n=2650)\end{array}$ & $\begin{array}{l}\text { Model 2 } \\
(n=2650)\end{array}$ & $\begin{array}{l}\text { Model 3 } \\
(n=2475)\end{array}$ \\
\hline $0-0.5$ (never) & 86 & $1.767(0.027)$ & $1.766(0.027)$ & $1.770(0.028)$ \\
$1-1.5$ & 232 & $1.818(0.017)$ & $1.813(0.018)$ & $1.817(0.018)$ \\
$2-3$ & 1054 & $1.840(0.010)$ & $1.834(0.010)$ & $1.839(0.011)$ \\
$3.5-4$ & 611 & $1.832(0.012)$ & $1.826(0.012)$ & $1.827(0.012)$ \\
$4.5-5$ (more than daily) & 667 & $1.855(0.011)$ & $1.845(0.012)$ & $1.850(0.012)$ \\
p value for trend & & 0.0089 & 0.024 & 0.031 \\
\hline
\end{tabular}

Model 1 adjusted for age, sex, height, town, instrument, observer, and room temperature.

Model 2 as for model 1 plus obesity and social class.

Model 3 as for model 2 plus cotinine and birth weight.

Table 4 Prevalence of wheeze in the past year and trends in FEV in wheezers and nonwheezers by fruit score

\begin{tabular}{|c|c|c|c|c|}
\hline \multirow[t]{2}{*}{ Fruit score } & \multirow[t]{2}{*}{ No.† } & \multirow{2}{*}{$\begin{array}{l}\% \text { wheezed } \\
\text { in last } 12 \\
\text { months }\end{array}$} & \multicolumn{2}{|c|}{ Mean (SE) adjusted* FEV ${ }_{1}$ (litres) } \\
\hline & & & Non-wheezers & Wheezers \\
\hline $0-0.5$ (never) & 83 & 25.3 & $1.756(0.032)$ & $1.763(0.054)$ \\
\hline $1-1.5$ & 223 & 13.5 & $1.829(0.019)$ & $1.724(0.045)$ \\
\hline $2-3$ & 1035 & 15.9 & $1.837(0.011)$ & $1.811(0.020)$ \\
\hline $3.5-4$ & 599 & 19.4 & $1.834(0.013)$ & $1.778(0.024)$ \\
\hline $4.5-5$ (more than daily) & 656 & 18.0 & $1.838(0.013)$ & $1.873(0.024)$ \\
\hline Test for trend $(\mathrm{p})$ & & 0.63 & 0.27 & 0.0019 \\
\hline Test for difference in trends $(p)$ & & & \multicolumn{2}{|c|}{0.020} \\
\hline
\end{tabular}

† Table based on 2596 subjects. Wheeze was missing on 54 of 2650 children.

Based on model 2.
Table 5 Mean (SD) plasma levels of vitamin $C$ and fruit score

\begin{tabular}{lrl}
\hline Fruit score & No. & $\begin{array}{l}\text { Plasma vitamin } C \\
(\mu \text { mol/l) }\end{array}$ \\
\hline $0-0.5$ (never) & 5 & $68.00(38.06)$ \\
$1-1.5$ & 23 & $50.16(13.91)$ \\
$2-3$ & 82 & $60.52(22.35)$ \\
$3.5-4$ & 53 & $58.79(20.34)$ \\
$4.5-5$ (more than daily) & 65 & $63.80(20.53)$ \\
\hline
\end{tabular}

values amongst high consumers. Indeed, the wheezers in this group had higher mean $\mathrm{FEV}_{1}$ values than the non-wheezers with the same levels of consumption, although the difference was not statistically significant.

OTHER SPIROMETRIC INDICES

Forced vital capacity (FVC) exhibited a similar graded relationship with the fresh fruit score $(p=0.019$ for trend, adjusted for model 3 confounders), the difference between the extreme groups being $132 \mathrm{ml}$ (95\% CI 53 to 210 ). Trends for $50 \%$ and $75 \%$ forced expiratory flow $\left(\mathrm{FEF}_{50}\right.$ and $\left.\mathrm{FEF}_{75}\right)$ were in the same direction but were not statistically significant $(\mathrm{p}=$ 0.49 and $\mathrm{p}=0.74$, respectively), the differences between the extreme groups being $69 \mathrm{ml} / \mathrm{s}$ $(95 \%$ CI -62 to 200$)$ for $\mathrm{FEF}_{50}$ and $12 \mathrm{ml} / \mathrm{s}$ (95\% CI -94 to 117 ) for $\mathrm{FEF}_{75}$. $4.5-5)(95 \%$ CI 32 to $144 \mathrm{ml})$. The results were similar for boys and girls (data not shown). Adjustment for additional potential confounding variables including obesity, social class, birth weight, and cotinine levels had little impact on either of the estimated effects. The difference between the high and low consumers was $79 \mathrm{ml}$ for model 2 and $79 \mathrm{ml}(95 \%$ CI 22 to 136 ) for model 3. While the low consumers stand out as having the lowest $\mathrm{FEV}_{1}$, there was evidence of a dose response across the other four groups, although this did not reach statistical significance $(p=0.20)$. Overall, restricting our analysis to children whose best test variation was less or equal to $5 \%$ produced similar results - for example, the difference between the two extreme groups was $97 \mathrm{ml}$ (95\% CI 35 to $158 \mathrm{ml}$ ) based on model 2 .

\section{WHEEZE}

Wheezing or whistling in the chest in the past year was reported by 450 of the 2596 children $(17.3 \%)$. There was no clear relationship between wheezing and fresh fruit consumption (table $4, \chi^{2}$ for trend $=0.23, \mathrm{p}=0.63$ ) except for a higher prevalence of wheeze $(25.3 \%)$ in those who never ate fresh fruit. This lack of relationship remained after adjusting for confounding variables such as town and social class. Adjusting for wheeze thus had little effect on the relationship between $\mathrm{FEV}_{1}$ values and fresh fruit consumption. However, in table 4 we see that $\mathrm{FEV}_{1}$ decreased with decreasing frequency of fresh fruit consumption more strongly in wheezers $(p=0.0019$ for trend) than in non-wheezers $(p=0.27$ for trend). The difference in trends was statistically significant $(\mathrm{p}=0.020)$ and was unaffected by further adjustment for cotinine levels and birth weight. It is noticeable that the trend amongst wheezers was particularly dependent on the high $\mathrm{FEV}_{1}$

\section{PLASMA VITAMIN C AND FRESH FRUIT} CONSUMPTION

Plasma vitamin C levels were available on 278 children in the last two towns; food frequency data were available on 228 of these and adequate $\mathrm{FEV}_{1}$ on 249. Table 5 shows the relationship between fresh fruit consumption and plasma vitamin C levels. There is a trend towards lower vitamin $\mathrm{C}$ levels with decreasing frequency of fresh fruit consumption, the vitamin C levels being some $13.5 \%$ lower in the least frequent consumers compared with the most frequent category. However, there is considerable variation in the vitamin $C$ levels within each group and the Spearman correlation coefficient was only $0.13(\mathrm{p}=0.055)$.

\section{PLASMA VITAMIN C, WHEEZE AND LUNG}

FUNCTION

The mean plasma vitamin $C$ level in 37 wheezers $(64.1 \mu \mathrm{mol} / \mathrm{l})$ was slightly higher than in 201 non-wheezers $(60.1 \mu \mathrm{mol} / 1)$, but the difference was not significant $(p=0.31,95 \%$ $\mathrm{CI}$ for difference -4.7 to $12.6 \mu \mathrm{mol} / \mathrm{l})$. There was no apparent correlation between $\mathrm{FEV}_{1}$ standardised for height, age, sex, and plasma vitamin $C$ levels, either overall (Spearman correlation coefficient $=-0.01, \quad \mathrm{p}=0.92)$ or amongst the 34 wheezers (Spearman correlation coefficient $=0.03, \mathrm{p}=0.88)$.

\section{Discussion}

These results support our prior hypotheses of an association between infrequent consumption of fresh fruit and impaired lung function in children. Our findings are consistent 
with all three previously published studies in adults ${ }^{1-3}$ though the existence of unpublished negative studies is of some concern.

\section{MAGNITUDE OF EFFECT}

The association is unlikely to be due to chance. Errors in the measurement of lung function and the crude nature of our dietary questionnaire suggest that the true relationship between ventilatory function and specific dietary constituents is probably stronger than it appears from this analysis. ${ }^{14}$ Despite the possible errors in ventilatory function and the crudity of our dietary measure, the estimated magnitude of the association found was not trivial. The difference in adjusted $\mathrm{FEV}_{1}$ between those eating fresh fruit more than once a day and those who never ate it was $79 \mathrm{ml}(95 \%$ CI 22 to $136 \mathrm{ml}$ ), a $4.3 \%$ deficit. This is very similar to a previous study using an identical food frequency questionnaire in adults which restricted its analysis to non-smoking asymptomatic subjects and found a deficit in $\mathrm{FEV}_{1}$ in low compared with high consumers of fruit of about $80 \mathrm{ml} .^{2}$ Our findings are also compatible with the $40 \mathrm{ml}$ difference between the highest and lowest tertiles of dietary vitamin $\mathrm{C}$ intake reported by NHANES II. ${ }^{1}$

Where our data are not clear is on the issue of dose response. While there is a suggestion of dose response across all the groups (table 3), subjects who almost never consume fresh fruit stand out as having a markedly lower $\mathrm{FEV}_{1}$. While our data are compatible with a dose response across the other groups, we lack clear evidence.

BIAS AND CONFOUNDING

Bias is an unlikely explanation for our findings since lung function was measured by nurses independent of parents returning the food frequency questionnaire. Moreover, both components were embedded in a much larger study and neither the nurses nor parents would have been aware of our interest in the specific hypothesis under study. A wide number of confounding variables were controlled for in our analysis including passive and active smoking, possible birth weight influences, and social class and town. That the estimated effect of fresh fruit consumption was little altered by adjustment for all these variables suggests that residual confounding is unlikely. While we had no measure of total calorie intake, adjustment for body size (height and obesity) had little effect.

We should be cautious of concluding that the critical nutrient is vitamin C. Fresh fruit and vegetable intake is as highly correlated with intake of other nutrients such as carotene, vitamin $\mathrm{A}$, and vitamin $\mathrm{E}$ as it is with vitamin C. ${ }^{15}$ It is therefore interesting that the only study to compare the effect of intake of different nutrients on lung function found that both vitamin $\mathrm{C}$ and vitamin $\mathrm{E}$ intake were related to $\mathrm{FEV}_{1}$, but that once vitamin $\mathrm{C}$ was controlled for there was no remaining association with vitamin $\mathrm{E} .{ }^{3}$ We need also to consider that frequent consumption of fresh fruit is associated with frequent consumption of other items. While fresh fruit was clearly the individual item most strongly related to $\mathrm{FEV}_{1}$, both green vegetable and salad consumption showed weaker but similar trends and a score based on all these items showed the strongest relationship of all. Such a finding is compatible with the recent report that magnesium intake is associated with better lung function and reduced bronchial reactivity. ${ }^{16}$ Magnesium is obtained from the diet, principally from cereals, nuts, green vegetables, and dairy produce. The frequency of consumption of other dietary items was not related to $\mathrm{FEV}_{1}$ in our study. The lack of any relationship with fish consumption is interesting given recent reports. ${ }^{17}$ However, our study may have lacked power given that few children ate fish more than once a week.

MODIFYING ROLE OF SYMPTOMATIC DISEASE

The association does not appear to be due to symptomatic disease per se; wheeze was not strongly related to fruit consumption and adjustment for it did not alter the relationship between $\mathrm{FEV}_{1}$ and our fresh fruit score. A previous study in adults found that reduced vitamin $\mathrm{C}$ intake was associated with a higher prevalence of wheeze. ${ }^{18}$ There was no evidence of that in our study, except for an increased prevalence of wheeze in children who never ate fresh fruit. Nor did we find any difference in plasma vitamin $\mathrm{C}$ levels between wheezers and non-wheezers. This contrasts with two previous studies which have reported lower levels of ascorbic acid in both the plasma and white cells in asthmatic subjects compared with control children ${ }^{19}$ and adults. ${ }^{20}$

However, there was evidence that the positive association between frequency of fruit consumption and $\mathrm{FEV}_{1}$ was stronger in subjects who had wheezed in the past year. A recent American study found that the effect of estimated vitamin $\mathrm{C}$ intake on $\mathrm{FEV}_{1}$ appeared somewhat stronger in adults with asthma and bronchitis, though not significantly so. ${ }^{1}$ Lack of statistical significance in that study could easily be due to the small number of subjects with symptoms. Several small studies have, in fact, looked for acute effects of vitamin C on airways reactivity. ${ }^{21-24}$ Two studies have reported that vitamin $\mathrm{C}$ inhibited decreases in $\mathrm{FEV}_{1}$ on exercise or after methacholine..$^{2122}$ Others have found no benefit in reducing the effect of a histamine challenge or on lung function. ${ }^{23} 24$

Our data suggest that the benefit of frequent consumption of fresh fruit and vegetables on $\mathrm{FEV}_{1}$ is restricted to children who wheeze. Given the lack of a relationship between wheeze and fresh fruit consumption, one interpretation is that the benefit is due to protection against bronchoconstriction in susceptible individuals which is compatible with a recent survey in adults. ${ }^{25}$ Such a conclusion would also explain why we find similar overall benefits in children to those seen in adults. However, all who wheeze do not exhibit bronchial hyperreactivity 
and the issue needs to be examined in a study where bronchial reactivity is measured before drawing conclusions.

\section{PLASMA VITAMIN C LEVELS}

Food frequency questionnaires are a crude but practical way of collecting dietary information on an epidemiological scale. Our attempt to validate our food frequency questionnaire as a measure of vitamin $\mathrm{C}$ intake by measuring plasma vitamin $\mathrm{C}$ in a subsample was disappointing. However, our results are comparable to those from a recent study in 6-10 year old American children. This study found a correlation between frequency of fresh fruit and vegetable consumption with serum vitamin C levels of only $0.29 .{ }^{15}$ In fact, there are several reasons why plasma levels of vitamin $\mathrm{C}$ and frequency of fresh fruit consumption may not be highly correlated: (1) a single measure of plasma vitamin C levels may be a poor marker of long term intake; and (2) there are other important sources of vitamin $\mathrm{C}$ in the British diet. ${ }^{26}$ In 1994 just under half the vitamin C in the British diet came from fresh fruit and fruit products while $40 \%$ came from vegetables, the most important being $12 \%$ from potatoes. ${ }^{27}$ In addition, there is the issue of vitamin supplements. We have been unable to identify any data on the prevalence of regular vitamin supplements in children in the UK. While these limitations may have clouded the relationship between frequency of fresh fruit consumption and plasma vitamin $\mathrm{C}$ levels, the relationship between fresh fruit consumption and lung function remains and requires an explanation.

We thank members of the Research Team (Sally Gassor RGN, Catherine Stuart RGN, Louise Went RGN, Angela Murphy RGN, Valerie Wilson RGN) and the schools, parents and children for their cooperation. Salivary cotinine measurements were carried out at the Medical Toxicology Unit, New Cross Hospital (Dr C Feyerabend)

This study was funded by The Wellcome Trust (grant no. 038976/Z/93/Z). MW was supported by the British Heart Foundation.

1 Schwartz J, Weiss ST. Relationship between dietary vitamin $\mathrm{C}$ intake and pulmonary function in the First National Health and Nutrition Examination Survey (NHANES I). Am f Clin Nutr 1994;59:110-4.

2 Strachan DP, Cox BD, Erzinclioglu SW, Walters DE, Whichelow MJ. Ventilatory function and winter fresh fruit consumption in a random sample of British adults. Thorax 1991;46:624-9.

3 Britton JR, Pavord ID, Richards KA, Knox AJ, Wisniewski $\mathrm{AF}$, Lewis SA, et al. Dietary antioxidant vitamin intake AF, Lewis SA, et al. Dietary antioxidant vitamin intake
and lung function in the general population. Am $\mathcal{F}$ Respir Crit Care Med 1995;151:1383-7.
4 US Department of Health and Human Services. The health consequences of smoking: chronic obstructive lung disease. A report of the Surgeon General. Washington DC: United States Government Printing Office, 1984

5 Anderson R, Theron AJ. Regulation by the antioxidants ascorate, cysteine and daspone of the increased extracellular and intracellular generation of reactive oxidants by activated phagocytes from cigarette smokers. Am Rev Respir Dis 1987;135:1027-32.

6 Whincup PH, Cook DG, Adshead F, Taylor S, Papacosta $\mathrm{O}$, Walker $\mathrm{M}$, et al. Cardiovascular risk factors in British children in towns with widely differing cardiovascular mortality rates. BMF 1996;313:79-84.

7 Whincup PH, Cook DG, Strachan DP, Papacosta O. Time trends in respiratory symptoms in childhood over a 24 year period. Arch Dis Child 1993;68:729-34.

8 Feyerabend C, Russell MAH. A rapid gas-liquid chromatographic method for the determination of cotinine and micotine in biological fluids. F Pharm Pharmacol 1990;42: $450-2$.

9 American Thoracic Society. Snowbird workshop on standardization of spirometry. Am Rev Respir Dis 1979;119: 831-8.

10 Jennings PE, Chirico S, Jones AF, Lunec J, Barnett AH Vitamin $C$ metabolites and microangiopathy in diabetes mellitus. Diabetes Res 1987;6:151-4.

11 Margolis SA, Ziegler RG, Helzlouer KJ. Ascorbic acid and dehydroascorbic acid measurement in human serum and plasma. Am f Clin Nutr 1991;54:13155-85.

12 Chinn S, Rona RJ, Gulliford MC, Hammond J. Weightfor-height in children aged $4-12$ years. A new index compared to the normalized body mass index. Eur $\mathcal{F}$ Clin Nutr 1992;46:489-500.

13 Rona RJ, Gulliford MC, Chinn S. Effects of prematurity and intrauterine growth on respiratory health and lung function in childhood. BMF 1993;306:817-20.

14 Freudenheim JL, Johnson NE, Wardrop RI. Nutrient misclassification bias in the odds ratio and loss of power in the Mantel test for trend. Int $\mathcal{F}$ Epidemiol 1989;18:232-8.

15 Byers T, Trieber F, Gunter E, Coates R, Sowell A, Leonard $\mathrm{S}$, et al. The accuracy of parental reports of their children's intake of fruits and vegetables: validation of a food frequency questionnaire with serum levels of carotenoids and vitamins C, A and E. Epidemiology 1993;4:350-5.

16 Britton J, Pavord I, Richards K, Wisniewski A, Knox A, Lewis S, et al. Dietary magnesium, lung function, wheezing, and airway hyper-reactivity in a random adult population sample. Lancet 1994;344:357-62.

17 Schwartz J, Weiss ST. The relationship of dietary intake to level of pulmonary function in the first National Health level of pulmonary function in the first National Health 7:1821-4.

18 Schwartz J, Weiss ST. Dietary factors and their relation to respiratory symptoms: the second national health and nutrition examination survey. Am f Epidemiol 1990;132: $67-76$.

19 Aderele WR, Ette SI, Oduwoule O, Ikpeme SJ. Plasma vitamin $\mathrm{C}$ (ascorbic acid) levels in asthmatic children. $A f$ $\mathcal{F}$ Med Sci 1985;14:115-20.

20 Olusi SO, Ojutiku OO, Jessop WJE, Iboko MI. Plasma and white blood cell ascorbic acid concentrations in patient with bronchial asthma. Clin Chim Acta 1979;92:161-6.

21 Mohsenin V, DuBois AB, Douglas JS. Effect of ascorbi acid on response to metacholine challenge in asthmatic subjects. Am Rev Respir Dis 1983;127:143-7.

22 Schacter EN, Schlessinger A. The attenuation of exercise induced bronchospasm by ascorbic acid. Ann Allergy 1982; 49:146-51

23 Malo JL, Cartier A. Lack of acute effects of ascorbic acid on spirometry and airway responsiveness to histamine in subjects with asthma. Allergy Clin Immunol 1986;78: 1153-8.

24 Ting S, Mansfield LE, Yarbrough J. Effects of ascorbic acid on pulmonary functions in mild asthma. F Asthma 1983; 20:39-42.

25 Soutar A, Seaton A, Brown K. Bronchial reactivity and dietary antioxidants. Thorax $1997 ; 52: 166-70$

26 Cade JE, Margetts BM. Nutrient sources in the English diet: quantitative data from three English towns. Int $\mathcal{f}$ Epidemiol 1988;17:845-8.

27 Ministry of Agriculture Fisheries and Food. National Food Survey 1994. London: HMSO, 1995. 